\title{
La diáspora silenciosa: estudios sobre la tercera ola de migraciones colombianas al exterior (2005-2015)*
}

\author{
Sebastián Polo Alvis** \\ ENRIQUe SERRANO LÓPEZ***
}

Artículo recibido: 29 de septiembre de 2017

Artículo aprobado: 12 de junio de 2018

Doi: http://dx.doi.org/10.12804/revistas.urosario.edu.co/desafios/a.6129

Para citar este artículo: Polo Alvis, S. \& Serrano López, E. (2019). La diáspora silenciosa: estudios sobre la tercera ola de migraciones colombianas al exterior (2005-2015). Desafíos, 31(1), 311-346. Doi: http://dx.doi.org/10.12804/revistas.urosario.edu.co/desafios/a.6129

\section{Resumen}

A pesar de que existe una larga tradición de migraciones al exterior en Colombia, durante los últimos diez años ha habido un aumento significativo como consecuencia de

\footnotetext{
* La presente investigación se realizó en el marco del Semillero de Migraciones Colombianas al Exterior (SEMICOEX) de la Universidad del Rosario.

** Politólogo de la Universidad del Rosario. Docente y coordinador del Semillero de Migraciones Colombianas al Exterior de la línea de investigación sobre Dinámicas y Asuntos Internacionales del Grupo de Estudios Políticos Internacionales (GEPI), de la Facultad de Ciencia Política, Gobierno y Relaciones Internacionales de la Universidad del Rosario. Correo electrónico: sebastian.polo@urosario.edu.co. OrCID: https://orcid.org/0000-0003-2950-6710.

*** Candidato a doctor en Filosofía de la Pontificia Universidad Javeriana. Magíster en Estudios de Asia y África del Colegio de México, y magíster en Análisis de Problemas Políticos Económicos Internacionales en la Universidad Externado de Colombia y el IEP de París. Comunicador social y filósofo de la Universidad Javeriana. Es profesor de planta e investigador de la Universidad del Rosario. Director del Semillero de Migraciones Colombianas al Exterior (SEMICOEX), proyecto sobre las dinámicas migratorias colombianas hacia el exterior en los siglos Xx y XXI. Correo electrónico: enriqueserrano3@gmail.com. ORCID: https:/ / orcid.org/0000-0001-9340-3236.
} 
eventos y circunstancias que han transformado abruptamente las condiciones de vida de la población colombiana. Este articulo se enfoca en estudiar el desarrollo de las tendencias de la tercera ola migratoria de la población colombiana al exterior entre los años 2005 y 2015, revisando los crecimientosy decrecimientos de dicha población hacia los destinos tradicionales, asi como en detectar la aparición de nuevos destinos, la naturaleza de las migraciones hacia estos y las estimaciones del número de colombianos en estos países durante este periodo.

Palabras clave: migraciones, Colombia, tercera ola, tendencias, destinos.

\title{
The Silent Diaspora: Studies of the Colombian Third Migration Wave (2005-2015)
}

\begin{abstract}
Even though there has been a long tradition of emigration from Colombia, only in the last ten years has there been a significant increase as a result of events and circumstances that have transformed the lives of Colombian citizens. This article focuses on studying the trends of the third Colombian diaspora wave between 2005 and 2015, reviewing the growth and decreases of the traditional destinations, as well as detecting the emergence of new destinations, in terms of the nature of migration to those destinations, and estimates of the actual number of Colombians in the recipient countries throughout this period.
\end{abstract}

Keywords: Migration, Colombia, third wave, trends, destinations.

\section{A diáspora silenciosa: estudos sobre a terceira onda de migrações colombianas ao exterior (2005-2015)}

\begin{abstract}
Resumo
A pesar de que tem havido uma longa tradição de migrações ao exterior na Colômbia, durante os últimos dez anos tem havido aumento significativo como consequência de eventos e circunstâncias que têm transformado abruptamente as condições de vida da população colombiana. Este artigo foca-se em estudar o desenvolvimento das
\end{abstract}


tendências da terceira onda migratória da população colombiana ao exterior entre os anos 2005 e 2015, revisando os crescimentos e decrescimentos de dita população aos destinos tradicionais, assim como em detectar a aparição de novos destinos, a natureza das migrações a eles, e as estimações do número de colombianos nestes países durante este periodo.

Palavras-chave: migrações, Colômbia, terceira onda, tendências, destinos.

\section{Introducción}

Colombia es un país de emigrantes. No obstante, a pesar de la diversidad de elementos que han configurado una prevalencia histórica de las migraciones de colombianos al exterior, la existencia de registros estadísticos que den un fiel seguimiento a la evolución de este fenómeno ha sido limitada o nula por parte de las autoridades colombianas. Dentro de la mencionada falta de información disponible, los registros sobre los últimos diez años han sido insuficientes para determinar el crecimiento de dicha población. Por lo tanto, este trabajo busca estudiar la evolución de los fenómenos migratorios propios de la tercera ola ${ }^{1}$ migratoria colombiana en el exterior.

Sin embargo, antes de abordar el objetivo propuesto anteriormente, es necesario hacer unas salvedades metodológicas del presente análisis. En primer lugar, este artículo busca actualizar y complementar los aportes estadísticos de los estudios previos que se han realizado sobre la diáspora ${ }^{2}$ con el fin de tratar de actualizar las cifras hasta las fechas más recientes posibles —existe un silencio censal de trece años, pero

\footnotetext{
1 El concepto de tercera ola, dentro de los estudios migratorios de la diáspora colombiana, es un concepto identificado por Cárdenas y Mejía (2006), que denota un crecimiento de la población migrante desde la segunda parte de la década de los noventa. Sin embargo, los autores proponemos como límite estadístico el año 2015 por razones de cambio tendencial en el crecimiento migratorio en algunos destinos en el que se identifica al retorno migratorio como una "cuarta ola migratoria" (Gutiérrez Bonilla \& Cubillos Novella, 2011) que no obedece a las mismas lógicas de los movimientos de salida, además de los nuevos procesos de recepción de migrantes de la diáspora venezolana en Colombia durante los últimos tres años.

2 Los autores del presente texto han preferido mantener reserva con respecto al concepto de diáspora, al ser un concepto amplio que se refiere a un movimiento humano desorganizado sin una tendencia definida. No obstante, se hace la salvedad de que no es un término lejano del tema de las migraciones y que, por lo tanto, está presente.
} 
en temas migratorios la ausencia de datos precisos por destino ronda los veinticinco años, desde el censo de 1993-. En segundo lugar, el trabajo prescindirá de la aplicación de un marco teórico, debido a que los análisis de causalidad de la revisión estadística no pretenden basarse en una perspectiva teórica sobre un fenómeno, sino en poder identificar los elementos coyunturales que han incidido en la evolución de las tendencias migratorias referidas. En tercer lugar, busca, a lo largo del texto, refutar la unicausalidad de la diáspora colombiana por el conflicto armado a pesar de su considerable influencia.

Por último, su justificación versa sobre la latente ausencia de información sobre el estado de las migraciones colombianas que materializa la necesidad de realizar aproximaciones estadísticas diversificadas, tanto en la existencia de cifras absolutas de población, como en la evolución de movimientos migratorios. En este instante, estamos a las puertas de un cambio de gran importancia en nuestras tendencias históricas de migración. Así sea por una situación coyuntural crítica, ajena al orden interno de Colombia, las circunstancias actuales nos impulsan a abordar las migraciones como un tema que debe ser de orden prioritario para el país. Para el desarrollo de este artículo, en primer lugar, es necesario hacer un análisis estadístico y causal sobre la diáspora colombiana durante los últimos diez años. A partir de lo anterior, se pretende identificar los cambios de las tendencias demográficas y estadísticas que se han manifestado mediante cifras y movimientos migratorios, tanto en destinos tradicionales como en nuevos destinos; cambios que serán abordados desde sus posibles causas. Por último, se revisarán las diversas implicaciones de los cambios en las tendencias de destinos y en los movimientos migratorios percibidos en este periodo, además de plantear las pertinentes conclusiones de este trabajo.

Dentro de los aspectos metodológicos de esta investigación, el abordaje de la tercera ola migratoria se realizará mediante dos formas de análisis. Por una parte, se implementará la revisión de elementos estadísticos como método de identificación de tendencias migratorias, basándose en número de migrantes con residencia permanente en los destinos señalados — ante la ausencia estadística de datos actualizados que puedan 
dar luz sobre la situación de la diáspora migratoria—, complementada con la revisión de datos de movimientos migratorios de salida de colombianos hacia otros países por concepto de residencia, trabajo y estudios, recolectados a través de los registros oficiales de la Unidad Administrativa Especial Migración Colombia vía derecho de petición. Por otra parte, se busca realizar un análisis de causalidad coyuntural de las tendencias migratorias identificadas como un elemento que permita hacer una aproximación de la realidad particular de los principales destinos migratorios de los colombianos. Estas estrategias buscan no solo suplir de estadísticas actualizadas hasta 2015 sobre las migraciones colombianas que se llevaron a cabo dentro del periodo de estudio, con sus correspondientes análisis de causalidad coyuntural, sino identificar los puntos de aumento de flujo mediante el estudio de las evoluciones de los movimientos migratorios.

\section{Evolución demográfica de las migraciones colombianas}

Las migraciones de colombianos al exterior han tendido a aumentar durante los últimos diez años como respuesta a condiciones políticas, socioeconómicas y culturales que han afectado tanto el número de colombianos emigrantes, como la aparición de nuevos destinos. $\mathrm{Al}$ nivel regional, Colombia ha sido el principal país sudamericano en el que ha habido una mayor emigración durante los últimos años, junto con Perú y Ecuador (OIM, 2012a). Esta dinámica se ha desarrollado recientemente como consecuencia de un crecimiento de los movimientos de salida de colombianos a principios de los años dos mil, causado "por las condiciones políticas internas imperantes, así como por los problemas de seguridad vinculados al narcotráfico" (OIM, 2012b: 14), así como por otros factores que serán mencionados en el desarrollo del trabajo.

A lo largo de los últimos cincuenta años, específicamente durante la década de los sesenta y de los setenta, las migraciones internacionales cobran real importancia en Colombia dado un "constante incremento de la salida de nacionales, sobre todo a Venezuela, Ecuador 
y Estados Unidos, y posteriormente hacia otros destinos" (Mejía Ochoa, 2012, p. 189), que se manifestó en la migración de 609647 personas hacia el exterior entre los años 1963 y 1973 (DANE, 2008). Esta cifra refleja "la primera ola de emigrantes colombianos, que entre los años sesenta y principios de los setenta tuvo como destino principal Estados Unidos y que se convirtió en el mito fundacional de la migración colombiana contemporánea" (Cárdenas \& Mejía, 2006; en Palma, 2015, pp. 11-12).

Durante las décadas de los setenta y de los ochenta, hubo una segunda ola migratoria hacia el exterior, en la que la cifra ascendió de 820615 colombianos en el exterior, en 1978, a 997667 en 1980, y a 1194455 en 1985 (DANE, 2008) —ver tabla 1-. Esta oleada se caracterizó, además de continuar con la migración hacia Estados Unidos (Palma, 2015), por una afluencia significativa hacia Venezuela y Ecuador causada por el auge petrolero de los años setenta. Dicha migración obedecía a un tránsito de personas "incentivado por la escasez de mano de obra, en particular agrícola, en áreas limítrofes, asociada a la emigración rural-urbana de la población local" (Mejía Ochoa, 2012, p. 190). Este aumento de la población colombiana en Venezuela "se efectuó en un momento de gran bonanza petrolera en el vecino país, acompañada de precios favorables en el mercado internacional" (Grupo Académico Colombia-Venezuela, 2015), que registró, en el censo de 1993, 2358259 colombianos en el exterior, lo que representó un aumento del $97,4 \%$, convirtiéndolo uno de los episodios migratorios de mayor crecimiento en la historia migratoria reciente. Dicho aumento también estaría directamente influenciado por un panorama de fuerte deterioro de la seguridad para muchos ciudadanos como consecuencia de la guerra contra organizaciones criminales dedicadas al narcotráfico.

A lo largo de los años dos mil, como resultado del empeoramiento de las condiciones políticas, económicas y sociales en Colombia, a causa de flagelos como el narcotráfico, la violencia generalizada, el duro deterioro de la seguridad para los ciudadanos, entre otros, se generó una tercera ola migratoria. Tras el cierre progresivo de fronteras en Estados Unidos, como efecto de la crisis de seguridad en 
Colombia y de los atentados del 11 de septiembre de 2001, "se diversificaron los destinos, lo que trajo como consecuencia la extensión de las migraciones hacia Europa, especialmente a España, así como a lugares no tradicionales en América Latina" (Echeverri, 2005; en Palma 2015, p. 12). Elementos que dispararon la diáspora como la violencia resultante del fracaso los Diálogos de Paz entre el gobierno colombiano y las FARC, en el año 2000, la crisis económica de 1999, y el progresivo auge de procesos de integración económica como la Unión Europea y el Mercosur determinarían las nuevas prospecciones migratorias de los colombianos en los siguientes diez años. Según registros del DANE (2005), el efecto colateral de dichos factores quedaría registrado en los números del Censo General de 2005, -3378345-, en los que se estimaba la distribución por destinos entre Estados Unidos (34,6\%), España (23,1\%), Venezuela (20\%) y Ecuador (3,1\%). Los resultados del Censo de 2005 evidencian un crecimiento, de la población emigrante en Colombia, de un $43 \%$ en un periodo de cincuenta años (ver tabla 1).

Como resultado de este crecimiento considerable, en el que se llegó a estimar la presencia de 4700000 colombianos en el exterior (ver tabla 1), el Estado colombiano tuvo que suplir la creciente necesidad de instaurar una política migratoria acorde a los intereses nacionales de entonces. De esta forma, se crearon diversas políticas direccionadas a plantear una normativa pertinente como el Programa Colombia Nos Une (CNU) en 2003, al igual que las jornadas preliminares de trabajo con comunidades de colombianos en el exterior que, junto con la entrada en vigor del documento CONPES 3603 de 2009, llevarían a desarrollar la Política Integral Migratoria (PIM), política direccionada a dar un tratamiento integral a cada una de las dimensiones de desarrollo de esta población y a mejorar la efectividad de los instrumentos utilizados para la implementación de estrategias y programas referentes a la población migrante (Cancillería, 2018). No obstante, de acuerdo con Janneth Clavijo,

El surgimiento y desarrollo del programa CNU está relacionado con marcos que se replican a nivel regional e internacional, que se condicen con una manera predominante de entender la migración, comprendida 
fundamentalmente desde la perspectiva de la gobernabilidad migratoria promovida por organismos como la OIM, entre otros [...] la relación Estado-migrantes parece formularse desde las demandas del Estado a los migrantes y no viceversa, en correspondencia con esta noción que legitima los procesos migratorios en tanto se constituyan en aportes, y los enmarca en lo que se denomina migración ordenada y regular, consecuente con esta definición y con los intereses que sostienen esta visión (2013, pp. 113-114).

De lo anterior, es posible decir que, a pesar de la existencia de iniciativas estatales de proponer una regulación para las problemáticas de la migración, no se ha desarrollado a profundidad una política migratoria sólida que salga de la lógica de comprensión exclusiva de la migración regular. Sin embargo, a pesar de este enfoque, y teniendo en cuenta las implicaciones derivadas de la ausencia estadística que impide la lectura correcta de la dimensión de la tercera ola, a continuación se procederá a revisar los procesos que han influido en la predominancia de destinos predilectos de migración del colombiano dentro del periodo de estudio de esta investigación, así como las nuevas tendencias existentes.

Tabla 1. Evolución histórica del número total de colombianos en el exterior, 1963-2017

\begin{tabular}{|c|c|c|c|c|c|c|c|c|}
\hline COLOMBIA & $\begin{array}{c}1963- \\
1973\end{array}$ & 1978 & 1980 & 1985 & 1993 & 2000 & 2005 & 2012 \\
\hline Total & 609.467 & 820.615 & 997.677 & $1^{\prime} 194.455$ & $2^{\prime} 494.925$ & $2^{\prime} 494.925$ & $3^{\prime} 378.345$ & $4^{\prime} 700.000$ \\
\hline
\end{tabular}

Fuente: Elaboración propia basada en información del DANE (2008) para 1978, 1980, 1985, 1993, 2000 y 2005. La cifra para el periodo entre 1963 y 973 se calculó mediante el promedio de estimados demográficos realizados por Arbeláez (1977), Ordóñez (1981), Perret y Rubiano (1983) y Baldión (1984), compilados por el DANE (2008). La cifra de 2012 es estimación de la Cancillería de la República de Colombia (2012).

\section{La búsqueda de un mejor porvenir: Estados Unidos y España}

A lo largo de la tercera ola migratoria de los inicios de los años dos mil, el incremento del número de colombianos en el exterior ha mantenido una tendencia de crecimiento al punto de llegar a cifras sin precedentes. Entre los años 2000 y 2015, en destinos como Estados Unidos y España, 
la cifra de emigrantes colombianos aumentó significativamente, lo que demuestra una continuación de la tendencia migratoria generada por la última oleada. En España, la cifra de colombianos entre 2001 y 2011 aumentó de 158164 a 379400 lo que refleja un incremento del 136\% en un periodo de diez años (INE, 2011) — ver gráfico 2-. Por su parte, según el United States Census del año 2010, la población colombiana en Estados Unidos ascendió a 658667 (OCDE, 2017) —ver gráfico 1-, en contraste con el censo de 2000 que registró 509872 colombianos, lo que representa un aumento del $29 \%$ en un lapso de diez años.

Aun así, durante los últimos años, en ambos casos el ritmo de esta proyección experimenta una desaceleración e, incluso, un descenso. Si se sigue el patrón de tendencia, entre 2010 y 2015 se evidencia la ralentización del crecimiento en ambos países, al registrarse la presencia de 699399 colombianos en Estados Unidos para 2015, y de 354108 en España para el mismo año. Lo anterior denota un crecimiento poblacional del 6\% para Estados Unidos, y una disminución del $6 \%$ para España (ver gráficos 1 y 2).

Dentro de las migraciones colombianas hacia estos países, existen ciertas similitudes en torno a la dispersión territorial de la población dentro de centros altamente urbanizados. En Estados Unidos, los colombianos se han asentado en estados como Florida, en la que se estima una población de 241984 nacionales, seguido de otros como Nueva York (102316), Nueva Jersey (78678), California (41 222), Texas (39994) y Georgia (20 828) (United States Census Bureau, 2017). En España, la migración para 2010 se ha concentrado principalmente en los mayores centros urbanos, en los que se calcula la residencia en la Comunidad Autónoma de Madrid de 80770 colombianos y en Cataluña de 65715 , además de tener una presencia significativa en comunidades autónomas como la Comunitat Valenciana (54 200), Andalucía (29 550), Islas Canarias (24655), Castilla - La Mancha (16650), Castilla y León (16410), y el País Vasco (15580) —ver gráfico 2-.

Ahora bien, el aumento de la migración colombiana hacia España es resultado de las profundas transformaciones políticas y económicas que 
Gráfico 1. Estado de la migración colombiana en Estados Unidos por dispersión territorial, proporción por género y población refugiada, 1970-2015

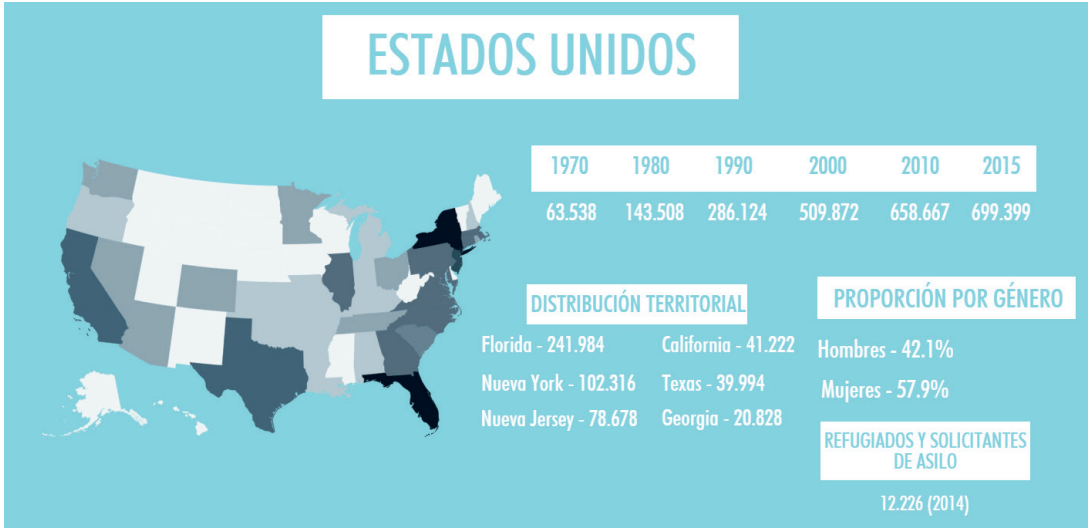

Fuente: Elaboración propia basada en información del US Census Bureau' Chapter 2: Growth and Composition of the Immigrant Population (2013). La distribución territorial está basada en información del USCB FactFinder (2017). Las cifras de Refugiados y Solicitantes de Asilo fueron tomadas de la Base de Datos de ACNur (2017).

Gráfico 2. Estado de la migración colombiana en España por dispersión territorial, proporción por género y población refugiada, 1991-2015

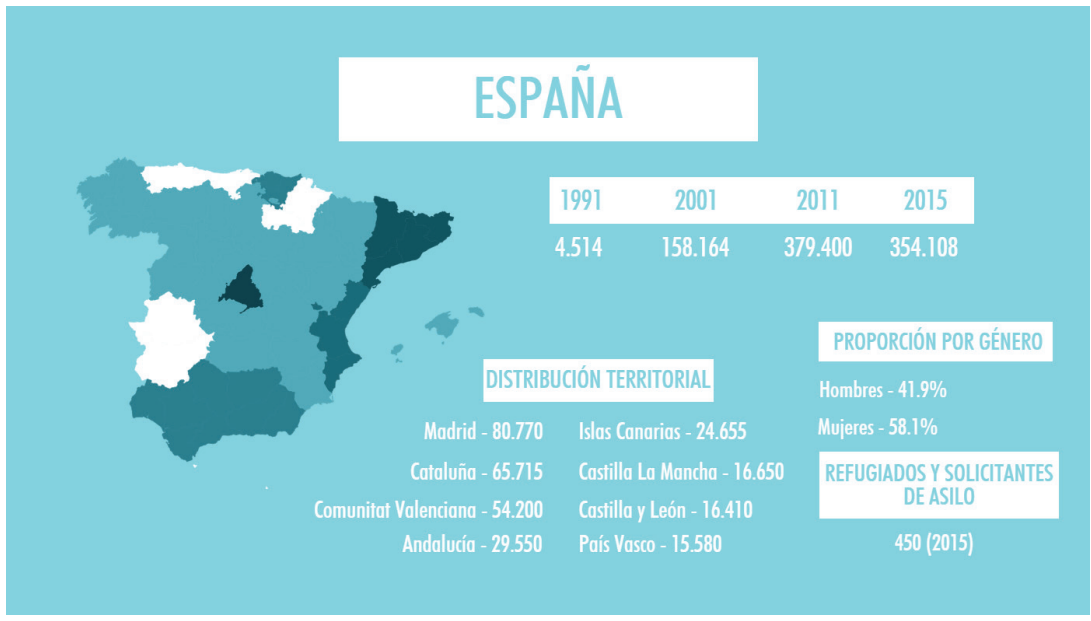

Fuente: Elaboración propia basada en información tomada de la Base de Datos sobre Migración de la OCDE (2017) y del INE (1991; 2001 y 2011). La distribución territorial está basada en información del INE (2011). Las cifras de Refugiados y Solicitantes de Asilo fueron tomadas de la Base de Datos de ACNUR (2017). 
experimentó dicho país a lo largo de los años ochenta y noventa, que derivaron en el incremento de "su atractivo como destino migratorio por la alta calidad de vida de la que disfruta, los beneficios sociales que ofrece a su población nativa y su situación política y económica" (Serrano, 2014, p. 5). Se evidencia un salto estadístico de $3403 \%$ entre 1991 y 2001 de la población extranjera en España (ver gráfico 2), además de las variaciones recientemente expuestas. Sin embargo, como consecuencia de la crisis económica de 2008 y de la existencia de otros destinos de la región económicamente atractivos como Francia y Alemania, que se mantuvieron estables durante este periodo - lo que desincentivó la migración laboral y la migración a largo plazo en este país-, tanto el número de colombianos en España como la cifra de movimientos migratorios hacia este destino comenzaron a experimentar descensos significativos (ver gráfico 2). Dicha disminución se percibe de manera más acentuada en los movimientos migratorios de naturaleza laboral, que disminuyeron entre 2008 y 2015 en un $62 \%$. Aunque la crisis económica no desincentivó del todo la migración colombiana hacia España, así como tampoco es la única razón de dicha variación, es posible interpretar su influencia como un elemento clave. Estas tendencias, junto con elementos internos del contexto colombiano, han impactado otras dimensiones de la migración como, por ejemplo, el número de refugiados. A pesar de que España no ha sido un destino histórico de refugiados colombianos, la tendencia migratoria dominante también se ve reflejada en esta dimensión, registrando 450 personas, en 2015, tras haber registrado picos de 1183 personas refugiadas y solicitantes de estatus en 2010 (ACNUR, 2017). Los descensos de población refugiada en España, además de demostrar un relativo desánimo sobre la opción de migrar a este destino, revelan la impertinencia de la justificación del conflicto armado como motivo principal de migración hacia este país.

Por otra parte, la tendencia al crecimiento de la población colombiana en Estados Unidos, además de las razones coyunturales de las situaciones políticas y económicas mencionadas antes, también obedece a una transformación progresiva de la percepción del país y del migrante colombiano en Estados Unidos. La suma de varios elementos como los avances del Estado colombiano en temas de seguridad y de 
lucha contra las drogas - específicamente en los temas referentes al Plan Colombia y a la política de Seguridad Democrática de Álvaro Uribe Vélez (2002-2010) — el aumento del ingreso promedio de la población colombiana, la presencia de varios periodos de reducción de la tasa de cambio frente al dólar, la paulatina reducción de filtros burocráticos en la expedición de visas estadounidenses, entre otros, permitió generar un escenario favorable para la migración de colombianos hacia este destino.

Asimismo, entre 2007 y 2015 se registraron 2544925 movimientos migratorios $^{3}$ de salida hacia Estados Unidos de colombianos que declaran tener residencia en el exterior (ver tabla 2). En este lapso, el número de movimientos migratorios hacia ese país aumentó en un 54\%, llegando a un punto máximo de 322753 en el año 2014. Además, otra evidencia de la premisa anterior reside en la evolución del número de refugiados en ese país, que pasó 30 866, en 2006, a solo 12226 en 2014 (ACNUR, 2017), lo que muestra una transformación de los objetivos y las prioridades de los colombianos al migrar, dejando de lado razones como el conflicto armado y los desplazamientos forzados. A partir de las cifras anteriormente mencionadas, es posible evidenciar una evolución dinámica de las migraciones hacia Estados Unidos tendiente a un crecimiento sostenido, lo que permite contemplar este país como el principal destino de migración de los colombianos.

En el ámbito laboral, Estados Unidos percibió un promedio anual, entre 2007 y 2015, de 37067 movimientos migratorios de colombianos por motivos de trabajo, alcanzando un acumulado de 306604 movimientos (ver tabla 3). Esto ubica a Estados Unidos como el principal destino para los colombianos desde un plano laboral, incluso si la

\footnotetext{
3 Si bien los movimientos migratorios pueden ser cifras que padezcan de casos de doble contabilidad, en el presente trabajo los autores apelan a estos números como herramientas para la lectura dinámica de las tendencias migratorias, más no como cifras absolutas. Las cifras de las tablas 2 y 3 solo contabilizan movimientos de salida de colombianos por concepto de residencia en el exterior, estudios y trabajo, cuya autoría es exclusiva de la Unidad Administrativa Especial Migración Colombia. No hay cómputos de balance de movimientos de entrada y salida en las cifras referenciadas.
} 
mencionada cifra no especifica la duración de estadía de los emigrantes. De 2007 a 2015, a pesar de las fluctuaciones, el incremento de estos movimientos fue de un $35 \%$, alcanzando un crecimiento máximo entre 2009 y 2014 de $55 \%$, y un decrecimiento entre 2008 y 2009 de $17 \%$, lo que pone en evidencia que, durante el periodo de estudio, las migraciones laborales tendieron al crecimiento.

En el plano educativo, Estados Unidos también resalta como el principal destino, con 6262 registros de estudiantes colombianos de educación superior para el año 2013 (Instituto de Estadística de la UNESCO, 2016a). En comparación con cifras de 2006 y 2009, años en los que se registraron 7078 y 6898 estudiantes respectivamente, se constata un descenso (Instituto de Estadística de la UNESCO, 2008 y 2011). No obstante, se registró un total de 130016 movimientos por motivo de estudios (ver tabla 3), es decir, un crecimiento de $122 \%$ entre 2009 y 2015, alcanzando un máximo de 20668. Por ende, a pesar de que el número de estudiantes decrece, Estados Unidos es todavía el destino principal de los colombianos en materia de educación, tanto en número de estudiantes como en volumen de movimientos migratorios.

En comparación con Estados Unidos, España difiere de sus escenarios respecto a los movimientos migratorios. A pesar de que es el tercer destino principal, la relación entre los movimientos migratorios por motivos de estudio y por razones laborales es distinta a la de Estados Unidos y, en algunos puntos del periodo de estudio, ambas tipologías tendieron a igualarse. Empero, España se ha consolidado como el segundo destino más concurrido por colombianos en temas educativos, al registrar 5754 estudiantes de educación superior en 2013, superando cifras de 2006 y 2009 en las que se contaron 929 y 4501 , respectivamente (Instituto de Estadística de la UNESCO, 2008 y 2011).

Además, entre 2007 y 2015 se han calculado un total de 48116 movimientos de salida de colombianos por concepto de estudios hacia España, con un pico de 6618 en 2011 y un máximo de crecimiento de $97 \%$ (ver tabla 3). Por otro lado, el total de movimientos migratorios de salida por razones laborales fue de 81098 para el mismo periodo, con un punto máximo, en 2008, de 17558 . Sin embargo, a pesar de 
que son cifras elevadas, los movimientos migratorios por concepto de trabajo han tendido a la baja, pasando de 15247, en 2007, a 6657 , en 2015, y con un pico negativo de 5792 en 2013 (ver tabla 3). Estos números concuerdan con los escenarios derivados de la crisis económica de 2008 que generó una progresiva pérdida del atractivo de España como destino de migración por motivos laborales, lo que se manifiesta en el aumento progresivo del número de desempleados que pasó de 2129 547, en 2007, a 3128 963, en 2008, y a 3982368 en 2010 (Instituto Nacional de Estadística - España, 2011).

En conclusión, Estados Unidos, a pesar de que se muestran algunas desaceleraciones en el crecimiento de la población y de los movimientos migratorios hacia este destino, sobre todo en temas estudiantiles, sigue siendo el principal destino de los migrantes colombianos. En el caso de España, incluso tras fortalecerse como destino educativo, las crecientes dificultades resultantes de la crisis económica han generado un paulatino decrecimiento del número de colombianos en este país, lo que insinúa un posible escenario de retorno o de migraciones hacia otros lugares de mayor atractivo económico. La predominancia de ambos destinos pone de manifiesto la prevalencia de condiciones propicias para el asentamiento de poblaciones colombianas, tales como la existencia de redes de cooperación entre migrantes, la familiaridad de la experiencia migratoria hacia este destino, la relativa proximidad cultural, entre otros factores que han contribuido al mantenimiento de las presentes tendencias.

Tabla 2. Flujos migratorios de salida de colombianos que declaran tener residencia en el exterior, 2007-2015

\begin{tabular}{|l|c|c|c|c|c|c|c|c|c|c|}
\hline $\begin{array}{c}\text { País de } \\
\text { residencia }\end{array}$ & $\mathbf{2 0 0 7}$ & $\mathbf{2 0 0 8}$ & $\mathbf{2 0 0 9}$ & $\mathbf{2 0 1 0}$ & $\mathbf{2 0 1 1}$ & $\mathbf{2 0 1 2}$ & $\mathbf{2 0 1 3}$ & $\mathbf{2 0 1 4}$ & $\mathbf{2 0 1 5}$ & Total \\
\hline $\begin{array}{l}\text { Estados } \\
\text { Unidos }\end{array}$ & 208359 & 217026 & 251098 & 299185 & 306504 & 308341 & 311065 & 322753 & 320621 & 2544925 \\
\hline España & 84623 & 82349 & 79534 & 83686 & 93157 & 85264 & 76237 & 71388 & 68845 & 724723 \\
\hline Venezuela & 19087 & 25749 & 19516 & 20069 & 29502 & 45183 & 41547 & 39740 & 31254 & 271647 \\
\hline Canadá & 11443 & 13248 & 14685 & 18516 & 21597 & 25150 & 25841 & 27770 & 28352 & 186602 \\
\hline Panamá & 9067 & 11539 & 14455 & 16310 & 19119 & 21194 & 22695 & 29940 & 38084 & 182403 \\
\hline Ecuador & 14160 & 13208 & 13739 & 16582 & 13742 & 13825 & 14527 & 17116 & 20455 & 137354 \\
\hline
\end{tabular}




\begin{tabular}{|l|c|c|c|c|c|c|c|c|c|c|}
\hline $\begin{array}{c}\text { País de } \\
\text { residencia }\end{array}$ & $\mathbf{2 0 0 7}$ & $\mathbf{2 0 0 8}$ & $\mathbf{2 0 0 9}$ & $\mathbf{2 0 1 0}$ & $\mathbf{2 0 1 1}$ & $\mathbf{2 0 1 2}$ & $\mathbf{2 0 1 3}$ & $\mathbf{2 0 1 4}$ & $\mathbf{2 0 1 5}$ & Total \\
\hline México & 10132 & 11181 & 11141 & 12665 & 15465 & 17355 & 17244 & 19098 & 20474 & 134755 \\
\hline $\begin{array}{l}\text { Reino } \\
\text { Unido }\end{array}$ & 6826 & 7617 & $\mathbf{7 6 0 2}$ & $\mathbf{8 1 5 0}$ & 10084 & 10273 & 11199 & 11894 & 12795 & 86440 \\
\hline Chile & 3013 & 3964 & 4443 & 5661 & 7416 & 10365 & 13288 & 17545 & 19805 & 85482 \\
\hline Argentina & 2069 & 2848 & 3762 & 5033 & 7479 & 10146 & 13785 & 14295 & 15214 & 74631 \\
\hline Italia & 6615 & 7398 & 6942 & 8049 & 9264 & 8943 & 8384 & 8347 & 8228 & 72170 \\
\hline Francia & 5298 & 5798 & 5916 & 7000 & 8329 & 8746 & 8555 & 9033 & 9159 & 67834 \\
\hline Costa Rica & 5696 & 6394 & 6626 & 7266 & 7570 & 7666 & 7818 & 7758 & 7655 & 64449 \\
\hline Brasil & 2546 & 3014 & 3249 & 4082 & 5069 & 6071 & 7302 & 8683 & 9545 & 49561 \\
\hline Perú & 2477 & 3131 & 3882 & 4545 & 5085 & 5913 & 6701 & 7854 & 8706 & 48294 \\
\hline
\end{tabular}

Fuente: Elaboración propia basada en información provista, mediante derecho de petición, por la Unidad Administrativa Especial Migración Colombia (2015).

Tabla 3. Flujos migratorios de salida de colombianos por conceptos de estudio o trabajo, 2007-2015

\begin{tabular}{|c|c|c|c|c|c|c|c|c|c|c|}
\hline $\begin{array}{c}\text { País de } \\
\text { residencia }\end{array}$ & 2007 & 2008 & 2009 & 2010 & 2011 & 2012 & 2013 & 2014 & 2015 & Total \\
\hline Estados & $9763 /$ & $9905 /$ & $9298 /$ & $11865 /$ & $14676 /$ & $16422 /$ & $17991 /$ & $20668 /$ & $19428 /$ & $130016 /$ \\
\hline Unidos & 29045 & 32848 & 28063 & 3128 & 31352 & 33419 & 37667 & 43662 & 39320 & 306604 \\
\hline \multirow{2}{*}{ España } & $3352 /$ & $3852 /$ & $4086 /$ & $5748 /$ & 6618/ & $6027 /$ & $5573 /$ & $6429 /$ & $6431 /$ & $48116 /$ \\
\hline & 15247 & 17558 & 8834 & 7022 & 7224 & 6183 & 5792 & 7081 & 6657 & 81098 \\
\hline \multirow{2}{*}{ Venezuela } & $5696 /$ & $7002 /$ & $2454 /$ & $3283 /$ & $4371 /$ & $8075 /$ & $10309 /$ & $7582 /$ & 10313/ & $59085 /$ \\
\hline & 34947 & 33876 & 24107 & 18592 & 17299 & 19669 & 13272 & 7619 & 5843 & 175224 \\
\hline \multirow{2}{*}{ Canadá } & $1293 /$ & $1641 /$ & $1524 /$ & $1704 /$ & $2596 /$ & $2867 /$ & $2792 /$ & $3221 /$ & $3144 /$ & $20782 /$ \\
\hline & 767 & 1093 & 657 & 697 & 768 & 868 & 935 & 916 & 971 & 7672 \\
\hline \multirow{2}{*}{ Panamá } & $1050 /$ & $856 /$ & $771 /$ & $976 /$ & $1622 /$ & $1953 /$ & $1693 /$ & $2467 /$ & $2156 /$ & $13544 /$ \\
\hline & 16802 & 20471 & 18014 & 20858 & 23052 & 23989 & 25015 & 28517 & 25376 & 202094 \\
\hline \multirow{2}{*}{ Ecuador } & $660 /$ & $524 /$ & $350 /$ & $602 /$ & $743 /$ & $837 /$ & 934/ & $1338 /$ & $1192 /$ & $7189 /$ \\
\hline & 16576 & 17965 & 16823 & 20142 & 20115 & 20134 & 23589 & 26817 & 21790 & 185951 \\
\hline \multirow{2}{*}{ México } & $1567 /$ & $1433 /$ & $1216 /$ & $1662 /$ & $2612 /$ & $3068 /$ & $3753 /$ & $4924 /$ & $5871 /$ & 26106/ \\
\hline & 9976 & 10862 & 8716 & 10371 & 11028 & 12006 & 15125 & 19110 & 19542 & 116736 \\
\hline Reino & $705 /$ & $751 /$ & $959 /$ & $1437 /$ & 2204/ & $1735 /$ & $2060 /$ & $3114 /$ & $3224 /$ & $16189 /$ \\
\hline Unido & 183 & 176 & 173 & 226 & 342 & 434 & 539 & 960 & 1351 & 4384 \\
\hline \multirow{2}{*}{ Chile } & $667 /$ & $666 /$ & $540 /$ & $801 /$ & $1378 /$ & $1680 /$ & $1793 /$ & $2282 /$ & $2045 /$ & $11852 /$ \\
\hline & 3143 & 3268 & 2813 & 4085 & 5367 & 6579 & 7739 & 8807 & 8312 & 50113 \\
\hline \multirow{2}{*}{ Argentina } & $2033 /$ & $2409 /$ & $2857 /$ & $4408 /$ & $6524 /$ & $6904 /$ & $6176 /$ & $7235 /$ & $6435 /$ & $44981 /$ \\
\hline & 3588 & 3750 & 3201 & 3946 & 4687 & 4673 & 5210 & 6294 & 5160 & 40509 \\
\hline \multirow{2}{*}{ Francia } & $1099 /$ & $1177 /$ & $1150 /$ & $1694 /$ & $2016 /$ & $1902 /$ & $2079 /$ & $2337 /$ & $2314 /$ & $15765 /$ \\
\hline & 1914 & 2025 & 1631 & 2190 & 2167 & 1856 & 1883 & 2286 & 1839 & 17791 \\
\hline
\end{tabular}




\begin{tabular}{|l|l|l|l|l|l|l|l|l|l|l|}
\hline $\begin{array}{c}\text { País de } \\
\text { residencia }\end{array}$ & $\mathbf{2 0 0 7}$ & $\mathbf{2 0 0 8}$ & $\mathbf{2 0 0 9}$ & $\mathbf{2 0 1 0}$ & $\mathbf{2 0 1 1}$ & $\mathbf{2 0 1 2}$ & $\mathbf{2 0 1 3}$ & $\mathbf{2 0 1 4}$ & $\mathbf{2 0 1 5}$ & Total \\
\hline \multirow{2}{*}{ Italia } & $\begin{array}{l}338 / \\
2687\end{array}$ & $\begin{array}{l}293 / \\
3302\end{array}$ & $\begin{array}{l}289 / \\
2823\end{array}$ & $\begin{array}{l}286 / \\
3247\end{array}$ & $\begin{array}{l}\text { 413/ } \\
3380\end{array}$ & $\begin{array}{l}443 / \\
3521\end{array}$ & $\begin{array}{l}539 / \\
4466\end{array}$ & $\begin{array}{l}674 / \\
4889\end{array}$ & $\begin{array}{l}645 / \\
4477\end{array}$ & $\begin{array}{l}3920 / \\
32792\end{array}$ \\
\hline \multirow{2}{*}{ Costa Rica } & $1217 /$ & $1321 /$ & $1212 /$ & $1715 /$ & $2791 /$ & $3312 /$ & $3896 /$ & $4530 /$ & $4140 /$ & $24134 /$ \\
& 8090 & 8994 & 7374 & 8263 & 9771 & 10662 & 12520 & 12716 & 10763 & 89163 \\
\hline \multirow{2}{*}{ Brasil } & $663 /$ & $671 /$ & $668 /$ & $1212 /$ & $1934 /$ & $2046 /$ & $1709 /$ & $2171 /$ & $2115 /$ & $13189 /$ \\
& 11650 & 13642 & 13730 & 15007 & 16121 & 17308 & 18882 & 21891 & 18903 & 147134 \\
\hline \multirow{2}{*}{ Perú } & $80 /$ & $92 /$ & $141 /$ & $309 /$ & $406 /$ & $480 /$ & $572 /$ & $738 /$ & $749 /$ & $3567 /$ \\
& 258 & 250 & 205 & 274 & 375 & 456 & 580 & 759 & 752 & 3909 \\
\hline
\end{tabular}

Fuente: Elaboración propia basada en información provista, mediante derecho de petición, por la Unidad Administrativa Especial Migración Colombia (2015).

\section{Migraciones transfronterizas en trance de cambio: Ecuador y Venezuela}

A diferencia de los destinos anteriormente estudiados, los casos de Venezuela y Ecuador han experimentado patrones migratorios de las migraciones colombianas que obedecen a situaciones más complejas. Debido a que son países que comparten fronteras extensas y porosas con Colombia, en las que hay un constante flujo de personas, y que participan en diversos escenarios de cooperación regional, conviven con elementos colaterales del contexto político colombiano. Problemáticas como el conflicto armado, el narcotráfico, el tráfico ilícito de migrantes, la trata de personas, entre otros, pueden incidir de una forma más profunda en las migraciones hacia estos destinos. A pesar de que estos dos países se distancian por el tamaño de la población colombiana radicada en su territorio, ambos escenarios comparten similitudes tanto en la creación de factores de atracción consecuentes a bonanzas económicas, como en la presencia de distorsiones estadísticas generadas por subregistros de población, además de espacios de tiempo más largos entre registros censales. Sin embargo, si se considera la presencia de estos problemas preliminares, se apela a los censos y cifras oficiales como herramientas para comprender de una forma más completa las tendencias migratorias vigentes para estos casos.

En Venezuela, el crecimiento de la población colombiana y la proporción porcentual frente a otros grupos de migrantes ha sido acelerado 
durante los últimos cincuenta años, calculando que el número de colombianos ascendió a 721791 (Instituto Nacional de Estadística - Venezuela, 2014). No obstante, dicho crecimiento percibido se sostendría, en un ritmo más lento, hasta 2015 , año en que se estima la presencia de 799796 colombianos, lo que representa un crecimiento de $10 \%$ en un lapso de cinco años (ONU, 2017) — ver gráfico 3-. Además, la representación porcentual de la población colombiana en torno al total de extranjeros en Venezuela oscila alrededor de $70 \%$, lo que determina la predominancia de esta población en este país.

Los colombianos en Venezuela están geográficamente distribuidos en los estados federales fronterizos de Zulia (193045) y Táchira (138 952), al igual que en otros como Miranda (98769), Distrito Capital (55650) y Carabobo (49133), además de contar con una presencia relevante en los estados de Lara, Barinas, Aragua, Bolívar y Apure (Instituto Nacional de Estadística - Venezuela, 2014) — ver gráfico 3-. Dicha dispersión es una gran evidencia de la tendencia a una migración de naturaleza transfronteriza, con propensión a la proximidad al territorio colombiano. El crecimiento progresivo de esta población obedece a dos episodios de expansión causados por la segunda y tercera olas migratorias de colombianos hacia el exterior. Durante los años setenta, la primera fase migratoria fue estimulada por el auge petrolero y minero. Pero dicho crecimiento se ralentizó en la década de los ochenta "con la caída de los precios del petróleo y la consiguiente recesión de la economía venezolana" (Grupo Académico Colombia-Venezuela, 2015). Sin embargo, a pesar de dicha crisis económica, la población colombiana mantuvo un crecimiento sostenido, lo que derivaría en el segundo episodio migratorio a finales de los años noventa.

Este se dio gracias a "la agudización de la confrontación armada colombiana", además de "los servicios ofrecidos por las misiones bolivarianas que provocaron el cruce de la frontera" (Grupo Académico Colombia-Venezuela, 2015), tales como los beneficios para el comercio transfronterizo patrocinados por los subsidios al consumo y, especialmente, las facilidades otorgadas por el Plan Nacional de Regularización y Naturalización de Extranjeros y Extranjeras del año 
2004, cuya misión consistió en regular la situación de " 273000 indocumentados - 186000 de ellos colombianos - muchos 'víctimas de extorsión y abusos', que llevaban hasta 30 años sin poder arreglar su situación", además de haber recibido "700 mil solicitudes de extranjeros, $85 \%$ de las cuales — 595000 solicitudes — fueron de colombianos" (Grupo Académico Colombia-Venezuela, 2015). Sin embargo, consideramos que las cifras expuestas por el gobierno venezolano rebasan los números de personas nacidas en Colombia registradas por el INE en 2011, lo que puede comprometer la veracidad de la información estipulada por el gobierno.

Ahora bien, según datos del Instituto Nacional de Estadísticas y Censos de Ecuador, en 2010 hubo registros de 89931 colombianos residiendo en el país. Sin embargo, es necesario hacer una salvedad sobre esta cifra. Es posible que exista un subregistro como resultado de la presencia de 120403 refugiados colombianos y 39744 solicitantes de refugio durante el mismo año del censo (ACNUR, 2017), lo que desvía las proyecciones estadísticas iniciales. No obstante, para 2015 se estimó un ascenso del número de colombianos en Ecuador: se registró la presencia de 194733 personas, lo que indica un incremento importante de $116 \%$ en un lapso de cinco años.

Aunque Ecuador no ha tenido una historia profunda como país receptor de inmigrantes, la representación porcentual de la población colombiana en comparación con las demás nacionalidades, al igual que en Venezuela, es mayoritaria a pesar de su tendencia a la baja. Por ejemplo, en 1950, alcanzó a representar un $62 \%$ de la población extranjera en Ecuador, pasando por 52,3\% en 1982, 51,3\% en 1990 , $49,5 \%$ en 2001 y $49,4 \%$ en $2010^{4}$. Los colombianos en Ecuador están distribuidos, geográficamente, sobre todo en las provincias de Pichincha (28383), Guayas (14272), Carchi (5870) y Azuay (5377), además de una fuerte presencia en las provincias de zona fronteriza

\footnotetext{
4 Los porcentajes fueron resultado de cálculos de los autores entre la totalidad del número de extranjeros en Ecuador y el número de colombianos para cada fecha, basados en información del INEC, citado por OIM (2011).
} 
como Sucumbíos (5167), Esmeraldas (3999), e Imbabura (3340); condición que comparte cierta similitud con el caso venezolano.

Esta distribución también obedece a las lógicas migratorias desarrolladas por la problemática de la proliferación masiva de solicitudes de refugio y refugiados, cuya cifra para 2014 ascendió a 121317 (ACNUR, 2017). Lo anterior se ha distribuido "de mayor a menor porcentaje, en las ciudades de Quito, Lago Agrio, Ibarra, Tulcán, Esmeraldas, Cuenca y Guayaquil"' (OIM, 2006, p. 20). Las migraciones colombianas hacia Ecuador se desarrollaron en dos fases: la primera, como consecuencia de la bonanza petrolera que duraría hasta mediados de los años ochenta, y que constituyó un total de 39443 colombianos para 1982 (ver gráfico 4). La segunda tuvo lugar a mediados de los años 2000 y 2001 en la, que según Mejía Ochoa,

\section{[...] tuvo como factor de atracción la dolarización de la economía ecua- toriana y como factor de expulsión el escalamiento del conflicto interno colombiano en la zona de frontera, motivado, en buena medida, por el desarrollo del "Plan Colombia", estrategia de lucha antisubversiva y contra el narcotráfico, financiada por los Estados Unidos (2012, p. 192).}

Estas razones no solo influyeron en un crecimiento estadísticamente formal de la población colombiana en Ecuador, sino también incidieron directamente en el crecimiento hipertrofiado del número de refugiados en dicho país, al punto de ser el principal receptor de personas con este estatus en la región (OIM, 2011). Sin embargo, además de las diversas lógicas del conflicto armado interno en Colombia, los elementos que determinaron el progresivo aumento de la migración regularizada a Ecuador y el impresionante crecimiento de la población, entre 2011 y 2015, son también elementos económicos y políticos. Por una parte, con el ascenso de Rafael Correa a la Presidencia (2007-2017), bajo el programa político de la Revolución Ciudadana, se constituyó una política migratoria sólida basada en la solución duradera de la problemática de los refugiados, en conjunción con la garantía de los derechos. Esta iniciativa estuvo acompañada por organismos internacionales como ACNUR. Por otra parte, Ecuador experimentó un auge económico sustentado en los altos precios del petróleo, en la progresiva inversión y en el gasto 
público en políticas de modernización de infraestructura; escenarios de gran atractivo para las migraciones laborales de los colombianos.

Durante los últimos diez años, las migraciones hacia estos destinos han experimentado cambios significativos en el volumen de los movimientos, lo que denota escenarios dependientes de realidades específicas de los países receptores. En el caso de Venezuela, las tendencias migratorias hacia este país edisminuyen de una forma acelerada. A pesar de ser el segundo destino, tan solo se registraron 271647 movimientos de salida de colombianos que declaran tener residencia fuera de Colombia hacia este destino, significativamente menos que hacia España (ver tabla 3). Sin embargo, el panorama no se detiene allí: los movimientos migratorios por razones laborales hacia Venezuela están en caída libre, pasando de recibir 34947 en 2007, a tan solo 5843 en 2015 (ver tabla 3).

Esta situación puede estar acorde con la creciente crisis económica y política de los últimos cinco años en Venezuela, de la que se desprenden problemáticas como la alta inflación, la polarización política violenta entre oficialistas y opositores, el incremento de la inseguridad en las grandes ciudades, el desabastecimiento de bienes de consumo diario, entre otros. Sin embargo, a pesar de estos decrecimientos, se resalta el continuo crecimiento del volumen de movimientos migratorios por estudios hacia Venezuela, en los que se destaca un crecimiento entre 2009 y 2013 de $320 \%$, alcanzando cifras que rondan los 10300 (ver tabla 3). Es probable que el crecimiento de esta tendencia se derive de los bajos costos de la educación en este país, además de las facilidades económicas que permite el tipo de cambio entre el peso colombiano y el bolívar venezolano, y de contar con una serie de políticas de educación subsidiadas por el Estado venezolano que permiten un mayor escalamiento de la migración estudiantil hacia este destino. Según información del Ministerio de Relaciones Exteriores de Colombia (2016), en el momento existen registros parciales del Sistema Integrado de Trámites al Ciudadano — SITAC — de que hay 5286 personas que declararon 
Gráfico 3. Estado de la migración colombiana en Venezuela por dispersión territorial, proporción por género y población refugiada, 1971-2015

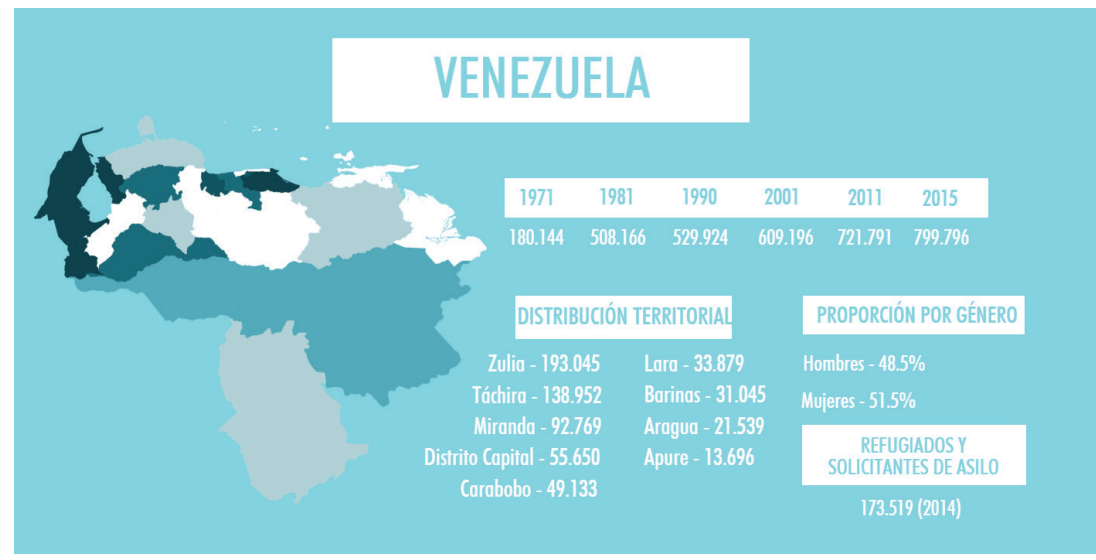

Fuente: Elaboración propia basada en información compilada por el Proyecto IMILA-Celade y REDATAM de la CEPAL (2017). La cifra de 2015 es estimada por la Organización de Naciones Unidas (2017). La distribución territorial está basada en información del INE (2011). Las cifras de Refugiados y Solicitantes de Asilo fueron tomadas de la Base de Datos de ACNur (2017).

\section{Gráfico 4. Estado de la migración colombiana en Ecuador por dispersión territorial, proporción por género y población refugiada, 1970-2015}

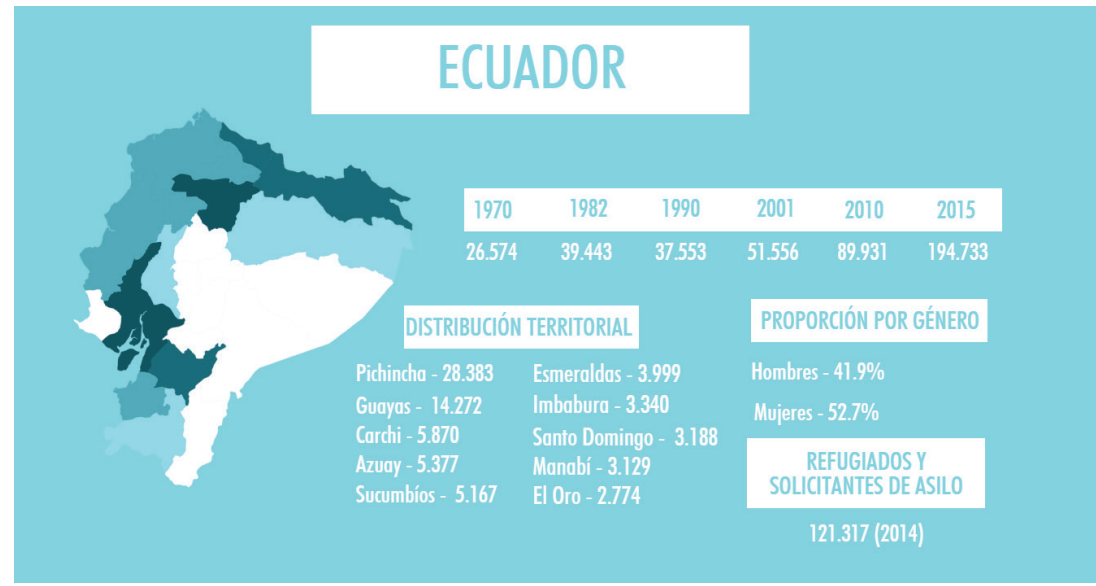

Fuente: Elaboración propia basada en información compilada por el Proyecto IMILA-Celade y REDATAM de la CEPAL (2017). La distribución territorial está basada en información de la OIM (2011). Las cifras de Refugiados y Solicitantes de Asilo fueron tomadas de la Base de Datos de AcNur (2017) 
adelantar estudios en territorio venezolano ${ }^{5}$, cifra que, relativamente, se equipara a la de España.

En el caso de Ecuador, a diferencia de Venezuela, se ha presenciado un incremento relativamente sostenido de los movimientos migratorios de colombianos entre 2007 y 2015. Con un total de 137354 movimientos de colombianos residentes en el exterior dentro de este periodo, para 2015 la cifra marcó un máximo de 20455 casos, alcanzando un crecimiento de $49 \%$ en relación con los registros de 2011 (ver tabla 2). Dentro del plano laboral, Ecuador es el tercer destino por número de movimientos migratorios de colombianos, con un acumulado de 185951 entre 2007 y 2015, tan solo superado por Estados Unidos y Panamá (ver tabla 3). Esta tendencia obedece a factores como la facilidad para acceder y radicarse en el país, la cercanía cultural y el profundo posicionamiento de las redes sociales de migrantes colombianos, así como un contexto de economía dolarizada que puede hacer rentable el envío de remesas hacia Colombia. En el plano educativo, se registraron 1506 estudiantes colombianos de educación superior en Ecuador para 2012 (Instituto de Estadística de la UNESCO, 2016a), además de mostrar un aumento del número de movimientos migratorios por motivos estudiantiles de $240 \%$ entre 2009 y 2015 (ver tabla 3). A pesar de que no es una población numerosa, al igual que el número de movimientos correspondientes a esta dimensión, los crecimientos experimentados en este destino pueden dar señales sobre Ecuador como un posible destino estudiantil a futuro.

Por último, es necesario hacer una salvedad respecto al estudio de las migraciones en estos países. Tanto Venezuela como Ecuador comparten unas experiencias similares en cuanto al tema migratorio: el subregistro censal y los arribos masivos de solicitantes de refugio. Por una parte, debido a las condiciones de permeabilidad fronteriza que existen en los límites con Venezuela y Ecuador, a la ausencia de un

\footnotetext{
5 Estimaciones basadas en información del Sistema Integral de Trámites al Ciudadano (SITAC) provista por el Ministerio de Relaciones Exteriores vía derecho de petición, otorgada el 3 de febrero de 2016.
} 
registro estricto de entrada y salida de personas, y a la facilidad para el traspaso de personas por esta frontera existe la posibilidad de que haya subregistros para ambos casos que pueden generar distorsiones en los censos tanto en el número de registrados y de residentes legales, como en la cifra de personas en condiciones de refugio. Por causa de esos fenómenos, las probabilidades de que existan grandes grupos humanos indocumentados en dichos países pueden causar imprecisiones que impiden tener un fiel reflejo de la realidad. Por ejemplo, según estimaciones de Naciones Unidas (2017) — ver gráfico 3-, se estima la presencia de 973315 y de 194733 colombianos en Venezuela y Ecuador. Si bien puede representar un posible escenario de crecimiento, debido a las condiciones de subregistro migratorio no existe una precisión sobre el estatus del número de personas estimadas, lo que es plausible a la luz de la interpretación de que dicha cifra se acerca a una lectura conjunta del número de migrantes regulares sumados al número de personas refugiadas o en condición similar a este estatus. Por ende, lo anterior permite hacer conexión con la segunda experiencia en común: los refugiados.

Como consecuencia de las avanzadas militares sobre las guerrillas y grupos paramilitares existentes a inicios de los años dos mil, que derivaron en el escalamiento del conflicto a lo largo del país, una parte de la tercera ola migratoria se dirigió hacia estos países como resultado directo de estos flagelos y ante la imposibilidad de una migración masiva hacia otros destinos mejor posicionados en el ámbito económico. Según Acnur (2017) — ver tabla 4-, en ambos casos se presenciaron episodios de crecimiento exponencial del número de refugiados colombianos, donde se destaca el incremento entre 2006 y 2007, en el que se pasó de registrar 11526 y 660 refugiados en Ecuador y Venezuela, respectivamente, a 264255 y 200843 , lo que representa un aumento de $2192 \%$ para Ecuador y de $30330 \%$ para Venezuela (ver tabla 4$)^{6}$.

\footnotetext{
6 Porcentajes calculados por los autores basados en la representación porcentual del crecimiento entre los años 2006 y 2007 frente a las cifras de 2006; registros tomados de ACNUR (2017).
} 
Empero, a pesar de estas imprecisiones, los números provistos por ACNUR concuerdan con las tendencias migratorias de los cuatro destinos estudiados, puesto que se manifiesta una reducción progresiva del número de refugiados en ambos casos, específicamente desde 2007, en Ecuador, y desde 2013, en Venezuela (ver tabla 4). Este cambio puede darse por razones que pueden justificar el retorno de colombianos hacia Colombia, tales como el deterioro económico, la presencia de mejores condiciones de vida en su país de origen, migraciones hacia otros destinos, entre otros. Además, el número de solicitudes de refugio hacia estos destinos se ha reducido considerablemente, pasando de 42469 en Ecuador y 14223 en Venezuela, en 2010, a 11468 y 251, en 2015, respectivamente (ACNUR, 2017).

Por último, a pesar del registro de crecimiento de la población colombiana, en Venezuela, de 799996 para 2015 (ver gráfico 3), la fuerte reducción progresiva de los movimientos migratorios de salida hacia ese país puede propiciar una alta probabilidad de una reducción del volumen de esta población. Por lo tanto, tras haber estudiado las dinámicas migratorias de las migraciones colombianas en estos destinos, en el caso venezolano se evidencia una disminución paulatina de dichos movimientos mientras que, en el caso ecuatoriano, sucede lo contrario. Dado el contexto político y social que ha afectado la reducción de la población colombiana en Venezuela, eventos tales como la expulsión de colombianos por parte del gobierno de Nicolás Maduro en 2015, el cierre de la frontera colombovenezolana el mismo año, además de la continuidad de las problemáticas derivadas del deterioro económico, la migración estudiantil hacia Ecuador ha tendido al crecimiento.

Por otro lado, a pesar de que el periodo de bonanza económica en Ecuador llegó a su fin, lo que implicó un gran endeudamiento público y un relativo deterioro de la economía y de las condiciones de vida de los ecuatorianos, las migraciones colombianas hacia este país seguirán manteniendo una fuerte relevancia. Si bien se percibió entre 2014 y 2015 un descenso de los movimientos migratorios por concepto laboral de $18 \%$, Ecuador mantiene un papel protagónico en el desarrollo de las tendencias migratorias de los colombianos en el exterior. 
Tabla 4. Evolución de la población refugiada y/o en condiciones similares en Ecuador y Venezuela, 2005-2016

\begin{tabular}{|l|c|c|c|c|c|c|c|c|c|c|c|c|}
\hline & $\mathbf{2 0 0 5}$ & $\mathbf{2 0 0 6}$ & $\mathbf{2 0 0 7}$ & $\mathbf{2 0 0 8}$ & $\mathbf{2 0 0 9}$ & $\mathbf{2 0 1 0}$ & $\mathbf{2 0 1 1}$ & $\mathbf{2 0 1 2}$ & $\mathbf{2 0 1 3}$ & $\mathbf{2 0 1 4}$ & $\mathbf{2 0 1 5}$ & $\mathbf{2 0 1 6}$ \\
\hline Ecuador & 9851 & 11526 & 264255 & 100657 & 115745 & 120403 & 122587 & 122964 & 122359 & 121317 & 120695 & 101207 \\
\hline Venezuela & 358 & 660 & 200843 & 201094 & 201244 & 201467 & 201941 & 203563 & 204259 & 173519 & 175495 & 172956 \\
\hline
\end{tabular}

Fuente: Elaboración propia basada en información de la Base de Datos de ACNUR (2017).

\section{Los nuevos horizontes del migrante colombiano}

Como consecuencia de los factores antes expuestos, las migraciones colombianas han diversificado sus rumbos. Dicho proceso ha influido en la aparición de nuevos destinos migratorios que, si bien dependen de unas realidades específicas determinadas de cada caso, pueden significar una aparición, a futuro, de nuevas tendencias de migración masiva en nuevos contextos y situaciones. Para realizar una revisión somera del estado actual de las migraciones hacia los nuevos destinos, los dividiremos en dos grupos: los países americanos y los no americanos.

En América, se fortaleció la presencia de colombianos en países como Canadá y Panamá (ver tabla 5). Se ha registrado la presencia de 60555 colombianos en Canadá en 2011, representado en un aumento de 55\% en comparación con el censo de 2006. Este destino se ha caracterizado por una alta tendencia a la migración estudiantil. Para 2012, había 672 estudiantes colombianos inscritos en un programa de educación superior en instituciones de este país (Instituto de Estadística de la UNESCO, 2016a). Además, se señala un aumento de 143\% de los movimientos migratorios por razón de estudios hacia Canadá entre 2007 y 2015, lo que señala al país norteamericano como un destino estudiantil altamente atractivo (ver tabla 3). Con respecto a los refugiados, se constata un ascenso en su número entre 2007 y 2015, al pasar de 13511 a 16428, pero también un descenso del número de solicitudes de refugio que va de 1461 hasta 274 (ACNuR, 2017). Se estima que para 2015, la población total ascendió a 70497 colombianos (ONU, 2017) —ver tabla 5-.

Por otro lado, también se registra un crecimiento en Panamá, cuya cifra más reciente es de 37408 colombianos para 2010, registrando 
un crecimiento de $77 \%$ en comparación con los cálculos del censo del año 2000 (ver tabla 5). Se destaca el crecimiento de los movimientos migratorios por motivos laborales hacia Panamá (ver tabla 3), y se resalta un incremento de $58 \%$ entre 2009 y 2014, alcanzando un máximo de 28517 movimientos. Respecto a los refugiados, se registra un aumento entre los años 2007 y 2015, al pasar de 1137 a 15551 en Panamá pero, a diferencia de Canadá, que registra aumentos moderados de las solicitudes de refugio dentro del mismo periodo, al pasar de 405 a 795 solicitudes (ACNUR, 2017). Se prevé que la cifra de colombianos residentes en este país haya alcanzado los 55251 para el año 2015 (ONU, 2017) —ver tabla 5-.

Dentro de la misma región, sobresalen los casos de Argentina y Chile, en donde se experimentó un crecimiento acelerado del número de colombianos entre 2001 y 2010, al registrar incrementos de 373\% y $367 \%$ entre 2001 y 2011. Entre las posibles razones que pueden explicar este crecimiento significativo, en el caso argentino, está el que ese país haya aumentado su atractivo como destino de migración estudiantil de bajo costo y como destino laboral de buena remuneración salarial en la región. Hay que resaltar la fuerte presencia de colombianos por razones académicas en Argentina (se registra un acumulado de 44981 movimientos migratorios por razón de estudios entre 2007 y 2015 -ver tabla 3-). La cantidad de estudiantes colombianos en Argentina se estima alrededor de 4481 para $2015^{7}$, pero es posible que el número de estudiantes colombianos que cursan o cursaron un tercer nivel educativo, para 2010 (superior no universitario, universitario y posuniversitario), haya ascendido a 11570 , de los cuales 5244 eran estudiantes de educación superior para el mismo año (CEPAL, 2017).

En el plano de las migraciones laborales, también se registran aumentos significativos, señalando incrementos de $97 \%$ de los movimientos hacia este país entre los años 2009 y 2014 (ver tabla 3). Por último, a pesar de que son cifras mínimas en comparación con otros casos,

\footnotetext{
Estimaciones basadas en información del Sistema Integral de Trámites al Ciudadano (SITAC) provista por la Cancillería de la República de Colombia vía derecho de petición, otorgada el 25 de noviembre de 2015.
} 
entre los año 2007 y 2015 se ha manifestado un crecimiento considerable del número de refugiados colombianos en Argentina, al pasar de 48 a 551, lo que representa un aumento de $1047 \%$, incremento causado por las iniciativas políticas de Argentina como país amigo del refugiado, por ACNUR y por políticas de gestión para el reasentamiento de refugiados. Se estima que para el año 2015, el crecimiento se haya ralentizado como consecuencia de condiciones de deterioro económico derivadas de la inflación, el encarecimiento del costo de vida, además del cambio de políticas migratorias gestadas desde la llegada de Mauricio Macri a la Presidencia, lo que incide en la reducción progresiva del crecimiento porcentual de los movimientos migratorios hacia este país y en el aumento de casos de retorno migratorio que permite la estimación que la cifra de colombianos descienda a 8640 para 2015 (ONU, 2017) — ver tabla 5-.

En el caso chileno, una de las principales razones por las cuales se puede explicar el crecimiento de la población colombiana responde a que se ha consolidado como un destino caracterizado por la migración estudiantil, en el que se registraron 1337 estudiantes para el año 2012 (Instituto de Estadística de la UNESCO, 2016a). Este crecimiento es significativo comparado con los registros del año 2000, en el que se contaron 130 estudiantes colombianos (Instituto de Estadística de la UNESCO, 2016b). Además, entre los años 2009 y 2014, se manifestó un crecimiento de los movimientos migratorios por concepto de estudios de $322 \%$ (ver tabla 3). No obstante, la razón principal de las que se resaltan es la migración por motivos laborales. Entre los años 2009 y 2014, se ha evidenciado un crecimiento sostenido de los movimientos migratorios de colombianos por motivos laborales que se calcula en un $213 \%$ (ver tabla 3), como resultado de un fuerte avance económico cuya razón es el auge de exportación de cobre, así como el progresivo crecimiento económico experimentado durante el periodo estudiado. Geográficamente, a pesar de que gran parte de los colombianos se ha asentado en la Región Metropolitana de Santiago - 15273 para 2016(Departamento de Extranjería y Migración del Ministerio del Interior y Seguridad, 2016), otros se han instalado en zonas del norte, entre las que prima la región de Antofagasta y, en menor medida, las regiones de Arica, Parinacota y Tarapacá, puesto que son zonas prósperas como 
resultado de sus actividades económicas por ser puntos fronterizos, portuarios y de extracción minera, entre las que se destaca la extracción cuprífera, que ha generado un "efecto llamado" que ha incentivado la búsqueda de trabajo en una región de altos ingresos fiscales.

Respecto a la situación de los refugiados, tanto la cantidad de esta población como la de las solicitudes han aumentado, pero también se registran periodos de decrecimiento. A pesar de que se apreció un incremento máximo de ambos elementos entre 2005 y 2008, al pasar de 416 a 1061 refugiados, y de 82 a 821 solicitudes de refugio, las cifras no han tenido grandes variaciones entre 2008 y 2014 (ACNUR, 2017). Con excepción de la reducción del número de refugiados entre 2008 y 2009, se ha registrado un crecimiento ralentizado entre 2010 y 2014 de $12 \%$, a diferencia del caso de las solicitudes de refugio, en el mismo periodo, que registró un incremento de $77 \%$ (ACNUR, 2017). Por último, se estima que la población continúe una tendencia al crecimiento, en la que se calcula que la población colombiana en Chile alcance un total de 23471 para el año 2015 (Departamento de Extranjería y Migración del Ministerio del Interior y Seguridad, 2016) — ver tabla 5-.

Cerrando este acápite, si nos remitimos a la información obtenida (ver tabla 5), es posible observar que también se ha fortalecido la presencia de colombianos en otros destinos intrarregionales, tales como Brasil, México y Costa Rica, así como en países de tránsito migratorio como Perú, que también obedecen a unas lógicas determinadas de sus contextos políticos, económicos y sociales. Sin embargo, a pesar de las diferentes razones por las cuales aumenta o disminuye la confluencia de colombianos hacia estos países, que son imposibles de abordar de una forma justa en este texto, es posible mencionar que se ha dado una profunda diversificación de los destinos migratorios.

Ahora bien, en el caso de los países no americanos, la migración de colombianos también ha aumentado, a pesar de que no ha sido de la misma proporción que en el caso de sus pares americanos. Las migraciones hacia los destinos europeos, al igual que las realizadas hacia Estados Unidos y Canadá, se han caracterizado por tener un control estricto sobre la entrada y salida de personas pero, paradójicamente, 
Tabla 5. Evolución histórica de la población colombiana residente en países americanos excepto Estados Unidos, Venezuela y Ecuador, c. 1990-2015

\begin{tabular}{|c|c|c|c|c|c|c|c|c|c|c|}
\hline Colombia & $\begin{array}{c}1990 \\
\text { (Año del } \\
\text { censo }\end{array}$ & $\mathbf{M}$ & $\mathbf{F}$ & $\begin{array}{c}2000 \\
\text { (Año } \\
\text { del } \\
\text { censo }\end{array}$ & $\mathbf{M}$ & $\mathbf{F}$ & $\begin{array}{c}2010 \\
\text { (Año } \\
\text { del } \\
\text { censo }\end{array}$ & $\mathbf{M}$ & F & $\begin{array}{l}\text { Est. } \\
2015\end{array}$ \\
\hline Argentina & $\begin{array}{l}2638 \\
(1991)\end{array}$ & 1172 & 1466 & $\begin{array}{l}3713 \\
(2001)\end{array}$ & 1731 & 1982 & $\begin{array}{l}17576 \\
(2010)\end{array}$ & 8517 & 9059 & 8640 \\
\hline Bolivia & $\begin{array}{c}529 \\
(1992)\end{array}$ & 218 & 311 & $\begin{array}{l}1244 \\
(2001)\end{array}$ & 600 & 644 & $\begin{array}{l}2086 \\
(2010)\end{array}$ & 1006 & 1080 & 2964 \\
\hline Brasil & $\begin{array}{l}2073 \\
(1991)\end{array}$ & 1062 & 1011 & $\begin{array}{l}4159 \\
(2000)\end{array}$ & 2290 & 1870 & $\begin{array}{c}6851 \\
(2010)\end{array}$ & 3450 & 3401 & 8179 \\
\hline Canadá & $\begin{array}{l}5660 \\
(1986)\end{array}$ & 2430 & 3230 & $\begin{array}{l}39145 \\
(2006)\end{array}$ & 18075 & 21070 & $\begin{array}{l}60555 \\
(2011)\end{array}$ & 28560 & 31995 & 70497 \\
\hline Chile & $\begin{array}{l}1666 \\
(1992)\end{array}$ & 736 & 930 & $\begin{array}{l}4097 \\
(2002)\end{array}$ & 1843 & 2254 & $\begin{array}{l}19137 \\
(2012)\end{array}$ & 7868 & 11269 & 23 471* \\
\hline Costa Rica & $\begin{array}{l}1678 \\
(1984)\end{array}$ & - & - & $\begin{array}{l}5898 \\
(2000)\end{array}$ & 2911 & 2987 & $\begin{array}{l}16514 \\
(2011)\end{array}$ & 7923 & 8591 & 21787 \\
\hline México & $\begin{array}{l}4964 \\
(1990)\end{array}$ & 2608 & 2356 & $\begin{array}{l}6018 \\
(2000)\end{array}$ & 2755 & 3263 & $\begin{array}{l}12832 \\
(2010)\end{array}$ & 5271 & 7561 & 20135 \\
\hline Panamá & $\begin{array}{l}13644 \\
(1990)\end{array}$ & 6786 & 6858 & $\begin{array}{l}21069 \\
(2000)\end{array}$ & 10376 & 10693 & $\begin{array}{l}37408 \\
(2010)\end{array}$ & 16748 & 20660 & 55251 \\
\hline Paraguay & $\begin{array}{c}189 \\
(1992)\end{array}$ & 84 & 105 & $\begin{array}{c}304 \\
(2002)\end{array}$ & 155 & 149 & $\begin{array}{c}297 \\
(2012)\end{array}$ & - & - & $\sim 1500$ \\
\hline Perú & $\begin{array}{r}2374 \\
(1993) \\
\end{array}$ & 980 & 1394 & $\begin{array}{r}4353 \\
(2007) \\
\end{array}$ & 1951 & 2402 & $\begin{array}{r}3214 \\
(2011) \\
\end{array}$ & 1201 & 2013 & 2937 \\
\hline $\begin{array}{l}\text { República } \\
\text { Dominicana }\end{array}$ & - & - & - & $\begin{array}{l}1552 \\
(2002)\end{array}$ & 769 & 783 & $\begin{array}{r}3416 \\
(2010)\end{array}$ & 1731 & 1685 & 3606 \\
\hline Uruguay & $\begin{array}{c}227 \\
(1985) \\
\end{array}$ & 107 & 120 & $\begin{array}{c}362 \\
(1996) \\
\end{array}$ & 172 & 190 & $\begin{array}{c}749 \\
(2012)\end{array}$ & 311 & 438 & 1780 \\
\hline
\end{tabular}

Fuente: Elabroación propia basada en información compilada por el Proyecto IMILA-Celade y REDATAM de la CEPAL (2017). Las estimaciones de 2015 son realizadas por la Organización de Naciones Unidas (2017), a excepción de Chile, de la cual se tomó el Departamento de Extranjería y Migración del Ministerio del Interior y Seguridad de la República de Chile (2016).

por ser un continente en el que se ha constituido un espacio común de tránsito de personas —espacio Schengen-, no tiene mayores controles dentro del mismo. Escenarios de integración como la Unión Europea han fortalecido el atractivo de algunos países de la región como destinos para migrantes, algunos de los cuales han tenido una historia como países receptores.

En el caso colombiano, las migraciones masivas hacia destinos no americanos son más bien ser recientes a causa de las fuertes restricciones 
migratorias hacia los colombianos. Dentro de los destinos en Europa, se destacan Italia, Francia, Reino Unido y Alemania; y, por fuera de Europa, países como Australia, en los que ha habido un crecimiento significativo del número de colombianos entre 2005 y 2015 (ver tabla 6). Si se hace una comparación con los destinos de migración americanos, es posible evidenciar que no ha habido crecimientos significativos, incluso si se parte de un panorama reducido por la falta de registros de algunos de los casos. En los tres casos mencionados, se ha mantenido un lento crecimiento de los movimientos migratorios tanto por motivos de estudio como por trabajo, con excepción del caso de las migraciones estudiantiles hacia el Reino Unido, en las que se ha calculado un crecimiento, entre 2007 y 2015, de $357 \%$. A pesar de que son regiones de altos ingresos y con un fuerte atractivo económico, razones como el costo de migrar, la distancia, la hostilidad del clima, o la incomodidad por la diferencia cultural, entre otras, pueden dar luces sobre el bajo crecimiento de cantidad colombianos en estos países.

En el plano estudiantil, los destinos no europeos se caracterizan por ser altamente atractivos para los estudiantes colombianos que, a lo largo del periodo de estudio, han aumentado en número. Se tienen registros (Instituto de Estadística de la UNESCO, 2016b) de que, para 2013, hubo 2476 estudiantes de educación superior inscritos en Francia, 1411 en Australia, 1382 en Alemania, 932 en Reino Unido, 862 en Italia, 334 en Suiza, 134 en Bélgica, 105 en Suecia y 49 en Noruega y, al sumar las cifras de España, se muestra un aumento significativo en los casos mencionados. Esto señala una diferencia diametral en comparación con los destinos americanos en temas de preferencia estudiantil debido al prestigio de las instituciones universitarias de estos países, de las opciones económicas de acceso a la educación superior pública, además de ser centros mundiales económicos y comerciales que ofrecen mejores oportunidades académicas y laborales para los estudiantes.

Por último, es posible considerar que la tendencia migratoria hacia estos destinos, especialmente los europeos, continúe en aumento, pero se realice a un ritmo más lento (ver tabla 6 ). A pesar de que en el año 2015 se retiraron las restricciones de visado a colombianos 
para realizar estadías de corta duración en los países que conforman el espacio Schengen, es probable que no se manifiesten migraciones masivas hacia estos destinos, lo que puede ser consecuencia del posible cierre progresivo del libre tránsito dentro de dicho espacio. Como resultado de la creciente crisis migratoria en Europa, causada por la guerra contra el Estado Islámico, en Medio Oriente - y que ha desembocado en una migración masiva y en la proliferación de poblaciones refugiadas en la región—, el ambiente para la migración se ha enrarecido y, ante la mencionada condición de emergencia, las facilidades para radicarse en estas regiones del mundo.

Tabla 6. Evolución histórica de la población colombiana residente en países no americanos, 2000-2015

\begin{tabular}{|l|c|c|c|c|c|c|c|c|c|c|}
\hline & $\mathbf{2 0 0 0}$ & $\mathbf{M}$ & $\mathbf{F}$ & $\mathbf{2 0 0 5}$ & $\mathbf{M}$ & $\mathbf{F}$ & $\mathbf{2 0 1 0}$ & $\mathbf{M}$ & $\mathbf{F}$ & $\begin{array}{c}\text { Est. } \\
\mathbf{2 0 1 5}\end{array}$ \\
\hline Alemania & 8880 & 2901 & 5979 & 9578 & 3008 & 6570 & 10294 & 3572 & 6722 & $\mathbf{2 2 1 1 6}$ \\
\hline Australia & 4180 & 2010 & 2170 & 5460 & 2370 & 3090 & 12420 & 5910 & 6510 & $\mathbf{1 5 4 9 7}$ \\
\hline Bélgica & 794 & 294 & 500 & 1252 & 479 & 773 & 1438 & 593 & 845 & $\mathbf{1 9 7 3}$ \\
\hline Francia & 16023 & 6874 & 9149 & 22606 & 10261 & 12345 & 27935 & 12226 & 15709 & $\mathbf{2 7 2 3 1}$ \\
\hline Italia & 14993 & 3437 & 11556 & 27259 & 8810 & 18449 & 36674 & 12864 & 23810 & $\mathbf{3 9 5 3 2}$ \\
\hline Noruega & 3472 & 1924 & 1548 & 4257 & 2308 & 1949 & 4973 & 2649 & 2324 & $\mathbf{5 6 9 3}$ \\
\hline $\begin{array}{l}\text { Reino } \\
\text { Unido }\end{array}$ & 11920 & 4802 & 7118 & 17569 & 7145 & 10424 & 24649 & 20171 & 14478 & $\mathbf{2 7 6 9 1}$ \\
\hline $\begin{array}{l}\text { Países } \\
\text { Bajos }\end{array}$ & 9588 & 4052 & 5536 & 11971 & 5045 & 6926 & 13296 & 5554 & 7742 & $\mathbf{1 4 3 7 5}$ \\
\hline Suecia & 7317 & 3892 & 3425 & 8896 & 4688 & 4208 & 10531 & 5382 & 5149 & $\mathbf{1 1 9 7 3}$ \\
\hline Suiza & 5701 & 2209 & 3492 & 8955 & 3694 & 5261 & 10460 & 3962 & 6498 & $\mathbf{1 1 9 4 9}$ \\
\hline
\end{tabular}

Fuente: elaboración propia basada en información de la OCDE (2017) y de la Organización de las Naciones Unidas (2017). Las estimaciones de 2015 son realizadas por la Organizaciones de Naciones Unidas (2017).

\section{Reflexiones y conclusiones}

Tras la revisión exhaustiva de las cifras, las evoluciones estadísticas y las posibles razones que nos permiten comprender de una forma aterrizada el desarrollo de la tercera ola migratoria de colombianos al exterior, cabe preguntarse por las diversas implicaciones que conllevan este crecimiento sustancial. Es posible afirmar que las migraciones colombianas han experimentado un crecimiento sin precedentes durante los últimos diez años, en el que la presencia de nacionales se fortaleció en 
destinos tradicionales, así como en la aparición de otros nuevos. La proliferación de estos, al igual que el crecimiento de las migraciones, son, posiblemente, pruebas fehacientes de que el migrante colombiano ha venido siendo aceptado de una forma más abierta dentro de nuevas realidades sociales. Las migraciones colombianas, a lo largo del periodo estudiado, han influido principalmente en los cambios de las migraciones internacionales en América Latina. No solo se rompió la limitada perspectiva de la exclusiva predominancia colombiana en las solicitudes de refugio de la región, sino que también se ha fortalecido la migración regular de colombianos como una tendencia migratoria ascendente al nivel regional y mundial.

A pesar de que, en nombre de los autores, se reconocen las diversas limitaciones que hay al desarrollar una investigación de esta clase dentro de un artículo de investigación, los resultados indagados y consolidados han permitido hacer una fotografía fresca de las condiciones de la migración regular de colombianos al exterior durante la tercera ola migratoria, lo que puede contribuir al debate académico y político sobre el fortalecimiento de una política migratoria que vaya más allá de intereses financieros. Respecto del conflicto armado, se concluye que la pertinencia de esta problemática, como elemento central de la proliferación de migraciones al exterior, es limitada debido a que existe una multiplicidad de elementos que condicionan a las personas a realizar las migraciones al exterior, dentro de las cuales se encuentran sus prioridades económicas y educativas en detrimento de las causas referentes al conflicto en sí. No obstante, se reconoce su influencia determinante en casos como Ecuador y Venezuela dentro de la proliferación de condiciones de subregistro migratorio que han impedido un dimensionamiento de dicha manifestación.

En conclusión, es posible ver que las migraciones son fenómenos que mutan con rapidez y que, a pesar de que haya escenarios históricos de migración hacia unos destinos determinados, elementos coyunturales como las transformaciones políticas, económicas y sociales siempre serán ventanas de oportunidades para la búsqueda de nuevos horizontes. Ahora que nos enfrentamos a la crisis humanitaria, derivada de la dictadura en Venezuela, que ha provocado la salida masiva de 
personas hacia nuevos destinos, hoy más que nunca es importante comprender nuestras tendencias migratorias para poder adquirir una capacidad de visión prospectiva sobre estos fenómenos. Es imperativo comprender las dimensiones de nuestro pasado y presente migratorio, no solo como un elemento vital para la construcción de una política de Estado, sino como un ejercicio propio de memoria y reflexión sobre nuestra responsabilidad de, esta vez, tender la mano a quien busca un porvenir más brillante en tierras ajenas.

\section{Referencias}

Alto Comisionado de las Naciones Unidas para los Refugiados (ACNUR). (2017). Population statistics database. Recuperado de http://goo.gl/ YZnXpz. Consultado el 12 de enero de 2017.

Cárdenas, M. y Mejía, C. (2006). Migraciones internacionales en Colombia: ¿Qué sabemos? Fedesarrollo. Working Papers Series, (30). Recuperado de http://goo.gl/ifx1GY. Consultado el 18 de febrero de 2017.

Cancillería de la República de Colombia. (25 de noviembre de 2015). Respuesta a Derecho de Petición S-GALC-15-115584. Información de acceso público mediante solicitud formal.

Cancillería de la República de Colombia. (2018). Documento CONPES 3603 de 2009. Recuperado de https://goo.gl/5VyuFJ. Consultado el 11 de mayo de 2018.

Clavijo Padilla, J. K. (2013). Los colombianos en el exterior en la política migratoria reciente: análisis del programa Colombia Nos Une. Revista Chilena de Derecho y Ciencia Politica, 4(3), 85-121.

Comisión Económica para América Latina (CEPAL). (2017). Investigación de la Migración Internacional en Latinoamérica - ImiLA. [Bases de datos de censos para países latinoamericanos y del Caribe]. Recuperado de http://goo.gl/RkVkLf. Consultado el 23 de enero de 2017.

Comisión Económica para América Latina (CEPAL). (2017). Red de Datos para Áreas pequeñas por Microcomputador - Redatam. [Bases de datos de censos para países latinoamericanos y del Caribe]. Recuperado de https://goo.gl/fGIU58. Consultado el 23 de enero de 2017. 
Departamento Administrativo Nacional de Estadística (DANE). (2005). Censo General de 2005. Recuperado de http://goo.gl/pTZrl. Consultado el 12 de enero de 2016.

Departamento Administrativo Nacional de Estadística (DANE). (2008). Estimación de la migración 1973-2005. Recuperado de http://goo. gl/zAqTYn. Consultado el 12 de enero de 2016.

Echeverri, M. (2005). Fracturas identitarias: migración e integración social de los jóvenes colombianos en España. Migraciones Internacionales, 3(1), 141-164.

Gutiérrez Bonilla, M. L. y Cubillo Novella, A. F. (2011). El retorno ¿una cuarta ola migratoria? El caso de Bogotá. En C. Prieto Dávila (coord.). Bicentenarios de Independencia en América Latina: construir el presente y el futuro, pp. 229-236. Madrid: Universidad Pontificia Comillas - Fundación superación de la pobreza.

Grupo Académico Colombia-Venezuela. (2015). Flujo migratorio de colombianos a Venezuela: las cifras cuentan. Recuperado de http://goo. $\mathrm{gl} / \mathrm{yJOVw} 4$. Consultado el 23 de enero de 2017.

Instituto de Estadística de la UNESCO. (2008). Global education digest: Comparing education statistics across the World. Recuperado de http:// goo.gl/UWYHR. Consultado el 23 de enero de 2017.

Instituto de Estadística de la UnESCO. (2011). Global education digest: Comparing education statistics across the World. Recuperado de http:// goo.gl/QoM7x. Consultado el 23 de enero de 2017.

Instituto de Estadística de la UNESCO. (2016a). Global flow of tertiary-level students: Colombia. Recuperado de http://goo.gl/tkzML. Consultado el 23 de enero de 2017.

Instituto de Estadística de la UNESCO. (2016b). Inbound internationally mobile students by country of origin: Students from Colombia. Recuperado de http:/ / goo.gl/er7q8E. Consultado el 23 de enero de 2017.

Instituto Nacional de Estadística - España. (2011). INEBase: Base de datos censal del Reino de España. Recuperado de https://goo.gl/LQfZy3. Consultado el 12 de enero de 2017.

Instituto Nacional de Estadística - Venezuela. (2014). XIV Censo Nacional de Población y Vivienda. Recuperado de http://goo.gl/KULTe4. Consultado el 12 de enero de 2016.

Instituto Nacional de Estadística y Censos - Ecuador. (2001). Censo de Población y Vivienda. Citado en Organización Internacional para las 
Migraciones (OIM). (2011). Perfil migratorio de Ecuador. Recuperado de https://goo.gl/bPQwhn. Consultado el 12 de enero de 2016.

Instituto Nacional de Estadística y Censos - Ecuador. (2010). Censo de

Población y Vivienda. Citado en Organización Internacional para las Migraciones (OIM). (2011). Perfil migratorio de Ecuador. Recuperado de https://goo.gl/bPQwhn. Consultado el 12 de enero de 2016.

Mejía Ochoa, W. (2012). Colombia y las migraciones internacionales. Evolución reciente y panorama actual a partir de las cifras.Revista Internacional de Movilidad Humana, 20 (39), 185-210.

Organización para la Cooperación y el Desarrollo Económicos (OCDE). (2017). International migration database. Recuperado de https:/ /goo. gl/hnKtdO. Consultado el 5 de febrero de 2017.

Organización Internacional para las Migraciones (OIM). (2006). Diagnóstico: necesidades y capacidades locales para brindar atención de emergencia a la población colombiana en búsqueda de protección internacional en Ecuador. Recuperado de http://goo.gl/Mh2Duf. Consultado el 12 de enero de 2017.

Organización Internacional para las Migraciones (OIM). (2011). Perfil migratorio de Ecuador. Recuperado de https:/ / goo.gl/bPQwhn. Consultado el 12 de enero de 2017.

Organización Internacional para las Migraciones (OIM). (2012a). Perfil migratorio de Colombia. Recuperado de http:/ /goo.gl/Kgfk27. Consultado el 12 de enero de 2017.

Organización Internacional para las Migraciones (OIM). (2012b). Panorama migratorio de América del Sur. Recuperado de https://goo.gl/ckCFh2. Consultado el 12 de enero de 2017.

Organización de las Naciones Unidas (ONU). (2017). Total international migrant stock report. Recuperado de https://goo.gl/2tWzpi. Consultado el 18 de abril de 2017.

Palma, M. (2015). ¿País de emigración, inmigración, tránsito y retorno? La formación de un sistema de migración colombiano. Revista del Observatorio de Análisis de los Sistemas Internacionales, 21(1), 7-28.

Serrano, E. (2014). Las condiciones socioculturales de la migración de latinoamericanos a España. En: D. Roll et al. La diáspora latinoamericana a España, 1997-2007: incógnitas y realidades, pp. 3-17. Bogotá: Editorial Universidad del Rosario. 
Unidad Administrativa Especial Migración Colombia. (20 de noviembre de 2015). Respuesta a Derecho de Petición - 20156222558632. Información de acceso público mediante solicitud formal.

U. S. Census Bureau. (2013). Growth and composition of the immigrant population. En F. Shama (coord.). The newest New Yorkers: Characteristics of the city's foreign-born population, pp. 9-22. New York: Department of City Planning of New York. Recuperado de https://goo.gl/u7USCS. Consultado el 18 de junio de 2017.

U. s. Census Bureau. (2017). UsCB FactFinder. Recuperado de https://goo. gl/he99HY. Consultado el 18 de junio de 2017. 